\title{
Los cambios en la industria de la música y el rol de las sociedades de gestión colectiva
}

\section{Changes in the music industry and the role of collective management societies}

\author{
Jorge Mendoza Woodman \\ Pontificia Universidad Católica del Perú \\ jmendozaw@pucp.edu.pe
}

\begin{abstract}
En este artículo se explora y analiza el rol de las sociedades de gestión colectiva dentro de los cambios de paradigmas que han ocurrido en los últimos años, tanto a nivel global como local, en la industria de la música. Se ha utilizado la teoría de agencia como marco teórico para explicar las razones de los continuos cuestionamientos y pedidos de cambios regulatorios presentados en contra de estas organizaciones, y se han explorado los avances tecnológicos como una alternativa para aumentar la capacidad de supervisión de los principales (los miembros de las sociedades de gestión colectiva) sobre las conductas de los agentes (los directivos de las mismas), planteando finalmente posibles mecanismos de gestión basados en la teoría del stewardship para el logro compartido de los objetivos institucionales.
\end{abstract}

Palabras clave: industria musical, sociedades de gestión colectiva, teoría de agencia, teoría del stewardship, derechos de autor, gestión cultural.

This article explores and analyzes the role of Performing Rights Organizations within the paradigm shifts that have occurred in recent years, both globally and locally, in the music industry. We used the agency theory as a theoretical framework to explain the continuous demands and requests for regulatory changes that have been made against this organizations, and explored the technological advances as an alternative to increase the monitoring capacity of the principals (members of collecting societies) on the behavior of the agents (its managers), and finally presenting potential management mechanisms based on the theory of Stewardship for the shared achievement of corporate goals.

Keywords: music industry, collecting societies, agency theory, stewardship theory, copyright, cultural management. 


\section{Introducción}

El poder que tiene una canción para movilizar y unir en su canto a miles de personas es algo muy difícil de explicar y de gran intensidad. Detrás de cada canción, nacida de la mente de una persona en un momento particular de su vida, se encuentra una industria musical que mueve actualmente miles de millones de dólares en el mundo. Esta aparente simpleza creativa contrasta con el complejo mundo en el que se ha convertido esta industria, donde proteger los derechos de la persona que tuvo la idea original -capaz de generar riquezas inimaginables - puede terminar siendo incluso más complejo todavía.

Este artículo explora y analiza el rol de las sociedades de gestión colectiva (SGC), instituciones creadas para proteger los derechos de propiedad de los compositores y artistas a la luz de los cambios que la tecnología ha ido introduciendo en la industria de la música. También examina cómo el problema de agencia que se genera ha originado serios cuestionamientos y pedidos de cambios regulatorios e intervenciones del Estado, no solo de parte de los usuarios de los productos musicales, sino también de sus propios asociados, los mismos compositores que buscan ser protegidos por ellas. Para realizar esta exploración y análisis se realizará una presentación la industria de la música y, a la par, una revisión del proceso de consolidación de nuevos paradigmas a raíz de los cambios tecnológicos e institucionales, ilustrando adicionalmente la forma como estos cambios se han presentado en la industria musical nacional. Luego se expondrá una breve historia de las SGC y su relación con los derechos de autor, para posteriormente explicar cómo funciona el sistema de gestión colectiva y examinar los principales cuestionamientos y retos a los que se enfrenta, presentando como ejemplo el caso peruano de la Asociación Peruana de Autores y Compositores (APDAYC). Finalmente, se planteará alternativas y estrategias de cambio en un entorno digital y bajo el marco de la teoría del stewardship.

\section{La industria de la música}

De acuerdo con lo publicado por Ángel Navas (2015) en el portal español Industria Musical, la industria de la música es un negocio global que, según la consultora $\mathrm{PwC}$, moverá para el año 2019 la suma de USD 50000 millones. Estos ingresos de la industria son generados por múltiples fuentes, las que se pueden agrupar en tres categorías principales: grabaciones (ventas musicales por medios físicos y digitales), música en vivo (conciertos y merchandising relacionado) y editoriales o publishing (Britten, 2009). Para entender mejor cómo se generan estos ingresos y la visión general tradicional de la industria de música, se presenta el gráfico 1, que servirá de base para el análisis de los cambios sufridos por este rubro en el tiempo y de su influencia en la gestión de los derechos de autor sobre las composiciones musicales.

En este gráfico, el artista musical (ya sea el mismo compositor de la música o aquel que utiliza composiciones ajenas) se relaciona con una compañía discográfica mediante un agente o mánager (usualmente, con el área encargada de artistas y repertorio —A\&R-). Esta compañía firma un contrato de exclusividad por un periodo de tiempo con el artista para grabar una o más producciones musicales, para lo cual la compañía consigue a un productor (el que aportará un cierto estilo y arreglos musicales al producto, así como 
relevancia/actualidad de acuerdo con el mercado musical al que está dirigido), un ingeniero de sonido responsable de la grabación musical y un estudio de grabación en donde esta se llevará a cabo. Una vez finalizada la grabación, la compañía disquera se encarga de la producción y distribución del producto musical (ya sea en físico o digital), y de las relaciones públicas, el marketing y la promoción de este a través de diferentes medios. De la misma manera, este artista, en conjunto con su mánager y un operador de espectáculos, organiza giras musicales para promocionar sus productos musicales en espectáculos públicos, en vivo y al aire libre, o en clubes cerrados y eventos privados. Finalmente, se realiza la gestión de los derechos del copyright (editoriales o publishing), ya sea sobre la ejecución de los productos musicales o de los derechos de autor por las composiciones grabadas y ejecutadas (Britten, 2009; David, 2010; Kretschmer, Klimis \& Wallis, 1999).

\section{Gráfico 1. La industria tradicional de la música}

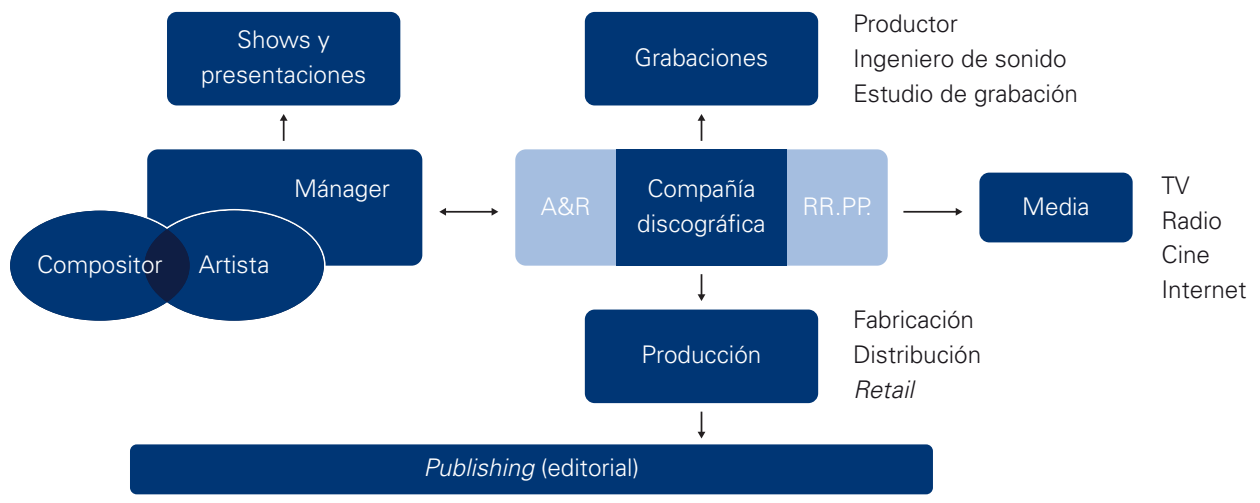

Fuente: adaptado de Britten (2009).

El modelo presentado en el gráfico 1 es cuestionado en la actualidad, existiendo diferentes investigaciones y publicaciones que demuestran que el paradigma «artista con un contrato con una compañía disquera que lo apoya y lo ayuda a crecer y ser exitoso» está desapareciendo. Según este modelo, normalmente los contratos celebrados por el artista le reconocen porcentajes bajos de las ventas como regalías a raíz del costo en marketing, promoción, producción, etcétera, efectuado por la compañía y a la poca capacidad de negociación de los artistas al iniciarse en este mercado. Dichos porcentajes fluctúan entre el 6\%, en el caso de los nuevos artistas, y el 24\% para las grandes estrellas (Kretschmer et al., 1999). Esto funciona así pues en el mundo artístico musical no hay forma de conocer el siguiente gran éxito de la industria y, por tanto, no existen garantías respecto a la inversión hecha por las compañías disqueras en un artista y un producto determinado (el caso del artista coreano Psy, el éxito de la canción "Let It Go» de la película Frozen — de Disney- o el más reciento caso del cantante venezolano Danny Ocean son buenos ejemplos). Se tiene un mercado donde la oferta creativa musical es mayor que la demanda de la misma, siendo esta oferta manejada por relativamente pocos intermediarios (compañías discográficas, clubes, publishers, etcétera), lo que singifica que en la visión tradicional de la industria los artistas nuevos o con poco renombre tienen escaso poder de negociación sobre su producto musical con los distribuidores musicales (Kretschmer, 2005). 
En esta situación, David (2010) plantea que, a pesar del poder que tienen estos "distribuidores de contenido" y del gran valor que extraen del mercado musical, su relación con los "creadores de contenido» nunca ha sido mutuamente beneficiosa; más bien, lo que ha habido y continúa existiendo es una relación de explotación, dado que la alternativa para estos creadores es no ser conocidos y no tener trabajo en el mercado musical.

\section{Los cambios en la industria de la música}

El mercado de la música ha pasado por profundos y múltiples cambios en los últimos 100 años, llenos de conflictos y enfrentamientos con el statu quo de la industria, en los que la tecnología ha tenido un rol fundamental tanto en su generación como en las nuevas alternativas y escenarios que se plantean. Este enfrentamiento se dio desde sus inicios, con la aparición del fonógrafo de Edison y los cilindros que utilizaba (luego reemplazados por discos de vinilo), hecho que retó al negocio de venta de partituras de música. Continuó luego con el desarrollo de la radio y, tiempo después, con el de la televisión, inventos que ampliaron el mercado musical a nivel mundial e introdujeron nuevos actores con capacidad de negociación en la industria, para desembocar actualmente en el mercado digital de la música de hoy, en donde los roles de los principales actores se encuentran cuestionados e incluso en franca desaparición (David, 2010; Handke, 2006; Kretschmer et al., 1999; Pitt, 2010).

En el gráfico 2 se pueden apreciar, tomando como base el gráfico anterior, los principales cambios que se han dado en la industria en los últimos años. Se observa que los creadores de contenido (compositores y autores) se mantienen como la base de la industria, pero ya no es necesario que exista un agente o mánager que los represente dado que dicho rol puede ser asumido por el propio artista, al igual que las actividades de producción, grabación y relaciones públicas que estaban a cargo de la compañía discográfica anteriormente.

Gráfico 2. Cambios y nuevos actores en la industria de la música

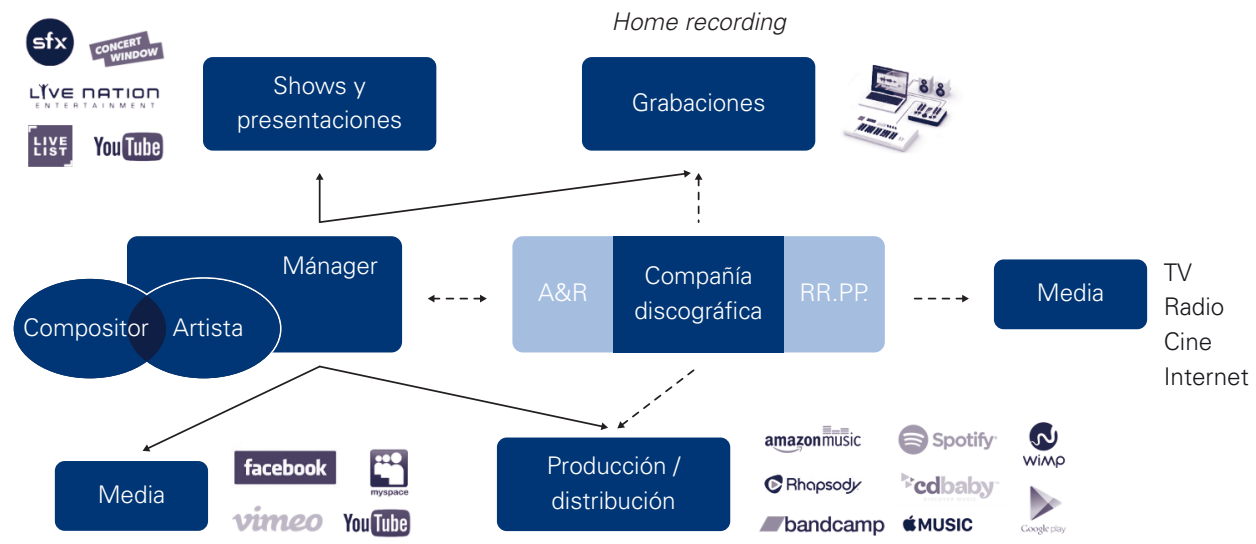


En relación con la actividad de grabación, los costos de los equipos y la tecnología necesaria para producir grabaciones con estándares de calidad a la altura de la industria musical han disminuido considerablemente. El home recording - grabaciones hechas en casa - ha permitido que los artistas/compositores accedan a la posibilidad de crear sus productos musicales y los tengan listos para distribuir a un costo muy bajo y en un corto tiempo. De la misma manera, la distribución y la venta del producto musical, que antes se realizaba a través de tiendas físicas especializadas o en retails, en la actualidad se da de manera digital, vía streaming ${ }^{1}$ y mediante descargas principalmente, sin necesidad de ocupar un medio físico (CD o vinilos) en tanto su consumo se realiza en reproductores digitales (Hull, Hutchison \& Strasser, 2010). En respuesta a ello, nuevos actores (por ejemplo, CDBaby, Amazon Music, Itunes y Spotify, por nombrar algunos) han aparecido para cubrir dicha distribución, ofreciendo plataformas para que los artistas/compositores coloquen directamente sus productos digitales; es decir, eliminando la necesidad de ser "descubiertos» por una compañía discográfica para estar disponibles en el mercado, lo que hace innecesario que una disquera les ofrezca grabar, producir y distribuir su material. El propio artista/compositor puede incluso hacer sus propias campañas de relaciones públicas a través de su página web o de plataformas de redes virtuales como Facebook o YouTube.

Finalmente, con respecto a los shows y presentaciones en vivo, han aparecido nuevos actores que buscan centralizar esas actividades, agrupando la gestión de locales, la venta de tickets y la contratación exclusiva de artistas, lo cual permite ofrecer contenido artístico relevante para diferentes nichos del mercado musical. Además, se ha popularizado la emisión de shows en vivo vía streaming a través de páginas como YouTube Live, Live List o Concert Window, lo que permite al artista tener mayor alcance, fuentes adicionales de generación de ingresos e incluso ofrecer su show al público directamente, sin intermediarios (David, 2010; Jones \& Bennett, 2015; McKinney, 2016).

En suma, cambios como los mencionados han contribuido a consolidar dos paradigmas perfectamente distinguibles en la industria, que serán revisados a continuación.

\subsection{Afianzar el rol de artistas que ejecutan productos musicales}

Hasta antes de la aparición del disco de vinilo, la forma principal de generar ingresos para los artistas era la ejecución de música en vivo: la performance o ejecución de shows artísticos. La posibilidad de vender productos musicales físicos dio un nuevo giro a la generación de ingresos para los artistas, fomentada por la aparición de las compañías discográficas y el negocio de la fabricación y distribución de discos musicales, lo que permitió la masificación y globalización de la industria de la música (David, 2010).

Como se visto anteriormente, los cambios en la industria y en la tecnología han hecho que la producción y distribución de los productos musicales digitales sea más barata y accesible para los artistas, lo que ha propiciado un incremento en su oferta; sin embargo, esto no ha generado un incremento en los ingresos de los artistas por la venta de productos

1. El término streaming se refiere a la transmisión de datos para archivos de audio y video que no necesita la descarga total de esos archivos para su reproducción, sino que, dependiendo de la velocidad de conexión, facilita el almacenamiento (buffer) de datos parciales. Estos, al llenarse, permiten la reproducción de dicho archivo mientras la descarga continua en un segundo plano. El lector puede encontrar más información sobre el tema en el siguiente link: $<$ www.ite.educacion.es/formacion/materiales/107/cd/video/video0103.html>. 
musicales. En simultáneo, los precios del producto musical también han disminuido, siendo el estándar actual la venta de una canción en formato digital a USD 0,99 en lugar de vender un disco con 10 o 12 canciones a USD 10, en promedio.

Según el reporte de la International Federation of the Phonographic Industry (IFPI), los ingresos del año 2016 por la venta de productos musicales (físicos, downloading, por suscripción y streaming) fueron de USD 15700 millones (IFPI, 2017; Smirke, 2015), monto muy importante que, sin embargo, muestra una disminución constante desde el año 2005, cuando se reportaron ingresos por USD 21000 millones (IFPI, 2006). La tendencia al consumo digital de la música vía downloads y streaming marcó un hito en el 2015 cuando las ventas digitales, 3,2\% mayores que las del 2014 (IFPI, 2016), fueron la principal fuente de ingresos (45\%) por primera vez en la historia de la industria musical, mientras que las ventas físicas ocuparon el segundo lugar con 39\%. Al año siguiente (2016), dicho porcentaje llegaría al 50\% de los ingresos (IFPI, 2017). Desde entonces, el futuro digital de la industria de la música es un hecho, lo que no significa necesariamente un mejor mercado para los creadores de contenido.

Contrariamente a esta disminución en los ingresos por venta de productos musicales, el mercado de ejecuciones o shows en vivo ha crecido no solo en cantidad, sino que también se han elevado los precios por entrada. De acuerdo con la investigación realizada por Alan Krueger en el 2004 (David, 2010), los precios de las entradas a los espectáculos en vivo se han ido incrementando todos los años desde 1997, acelerándose este incremento con la aparición de la tecnología de intercambio de archivos (file-sharing). En su investigación, Krueger plantea que la relación entre el artista y el promotor del show artístico es más igualitaria y beneficiosa para ambos que la existente entre el artista y la compañía discográfica, en la cual usualmente se le reconoce un bajo porcentaje de los ingresos. Desde esta perspectiva, se puede inferir que esa disminución y el cambio en las ventas de productos musicales no son necesariamente negativos, sino que terminan siendo beneficiosos para los artistas musicales ejecutantes.

\subsection{Concentración de las compañías discográficas y cambios de estrategia}

Tras la compra, en el año 2012, de EMI Distribution por parte de Universal Music Group (UMG), el grupo de las cuatro grandes o Big Four (Sony, Warner, Universal y EMI) se redujo a solo tres, repartiéndose los ingresos por la venta de música (física y digital) de la siguiente manera: UMG con el 39,19\%, Sony con 30,25\%, Warner con 19,15\% y el resto con $11,42 \%$ (Nielsen Company, 2013). Estas fusiones y compras entre las grandes compañías son solo una muestra más de cómo el negocio de la industria está cambiando y buscando espacios con mayores oportunidades para generar ingresos o reducir costos. Y uno de esos espacios es el de los ingresos por derechos por publishing (editoras musicales).

Los ingresos por publishing musical incluyen la venta de partituras, la ejecución de shows en vivo, el uso de música en televisión, cine o como música de fondo, etcétera, y tradicionalmente eran manejados por compañías diferentes a las compañías disqueras, cuyo cobro siempre ha sido complejo y complicado; sin embargo, las compañías disqueras manejan los catálogos musicales de las producciones de los artistas y muchas tienen derechos contractuales sobre los mismos. En ese contexto, a la luz de la disminución de 
las ventas de discos y dado que la digitalización permite un mejor control y monitoreo del uso del producto musical, la oportunidad de consolidar un nuevo mercado estaba dada (David, 2010).

En su libro The Music Business and Recording Industry, Hull, Hutchison y Strasser (2010) relatan cómo las Big Four fueron adquiriendo poco a poco las principales compañías editoriales de música, manejando ellas solas para el 2008 el 65\% de un mercado de USD 2000 millones. De ese total, un 5\% está repartido entre seis editoriales medianas y el 30\% restante está dividido entre unas 20000 empresas que gestionan derechos individuales. La importancia del negocio de la editorial o publisher, y la razón del interés y cambio de la estrategia de negocio por parte de las compañías disqueras, se basa en las muchas posibilidades de generar ingresos por diversas fuentes y prolongado tiempo que una canción medianamente exitosa es capaz de ofrecer.

Hull, Hutchison y Strasser (2010) describen este proceso de creación de ingresos por parte de las editoriales a partir de la adquisición y explotación de canciones. La «adquisición» se relaciona con actividades usualmente llevadas a cabo por el área de $A \& R$ de la editorial musical, encargada de ubicar y firmar a compositores y sus canciones con potencial para incrementar su catálogo. En este modelo, el compositor (tanto de la letra como de la música) usualmente recibe el $50 \%$ de las regalías. La "explotación» de la canción, por otro lado, es el conjunto de modalidades a través de las cuales la editorial coloca en el mercado musical las canciones, tales como la grabación de una canción original por parte de un artista o en diferentes versiones de otros artistas (covers de la canción original), su venta de manera física o digital, la ejecución de estas en presentaciones en vivo, su uso como música para series de televisión o en películas (sincronización), la venta de partituras musicales, su difusión por radio o en streaming, su uso como música de fondo en establecimientos o como pistas en un karaoke, etcétera, lo que significa que los ingresos que se generan por esta explotación quedan en la misma compañía discográfica, gestionados por su empresa editorial. Finalmente, hay que tener en cuenta que una canción va a generar rentas cada vez que es utilizada en cualquiera de estas modalidades, por lo que puede ser una fuente constante de dinero a futuro que requiere una baja inversión en el presente, siendo un ejemplo de esto la canción «Happy Birthday», que genera un estimado de USD 2 millones por regalías al año (Weiser, 2013).

Estos cambios en la industria de la música han producido también cambios en los roles de los principales actores, donde los intereses se han redirigido mayoritariamente hacia los "creadores de contenido», alejándose poco a poco de los "distribuidores de contenido", que se encuentran ahora en proceso de adaptación a un mundo digital con muchos intermediarios, que operan en mercados de consumo masivo global y ofrecen sus servicios a precios fijos o muy bajos.

\section{Los cambios en la industria musical en el Perú}

De acuerdo con la consultora PwC (2016), el mercado musical peruano estaba valorizado en USD 28 millones en el año 2014, USD 3 millones menos que el año 2013; y pronosticaban un continuo decrecimiento hasta llegar a USD 22 millones el año 2019 (Gestión, 2015c). De acuerdo con su análisis, el mercado musical peruano es uno de los más pequeños de 
Latinoamérica (los primeros lugares los tienen el mercado brasilero con USD 325 millones y el mexicano con USD 245 millones), debido principalmente al fácil acceso a copias piratas, las descargas ilegales en Internet y a la baja penetración del Internet móvil, lo que dificulta la oferta legal musical y su consumo digital.

Por otro lado, la industria musical nacional no ha sido ajena a los cambios de la industria mundial detallados anteriormente. Los distribuidores de contenido en el Perú (disqueras, discotiendas, radios y medios, etcétera) han tenido que adaptarse a estos cambios, tal como fue el caso de la discotienda Phantom, que introdujo nuevas líneas de negocios y actividades conectadas con otros rubros del entretenimiento (Gestión, 2015b), mientras las grandes disqueras (Sony, Universal y Warner) dejaban de tener oficinas de representación local. En el caso de las disqueras nacionales, como El Virrey y IEMPSA —esta última que llegó a vender hasta 40 millones de discos anuales-, han desaparecido como tales, vendiendo a terceros su catálogo de canciones y funcionando hoy en día principalmente como estudios de grabación (El Comercio, 2014; IEMPSA, 2016; Sifuentes, 2013). Esta situación ha dado pie a la aparición de disqueras pequeñas e independientes enfocadas en nichos musicales, las cuales han desarrollado circuitos propios de promoción, difusión y distribución para sus catálogos de artistas (Amorós, 2014; PuntoEdu, 2015).

A la par, han aparecido nuevos distribuidores de contenido especialmente enfocados en la distribución digital de músicos nacionales, destacando el caso de Bquate como distribuidor y el de Movistar Música para la promoción en medios. Bquate es un sello discográfico peruano y además una distribuidora de música online creada el año 2014, ganadora del premio a la mejor startup IBM SmartCamp el año 2015. Actualmente, representa a más de 600 artistas latinoamericanos, habiendo distribuido más de 2000 canciones de músicos peruanos a diferentes tiendas online y de music streaming del mundo, como Itunes y Spotify (Bernui, 2016; La República, 2015b; Telefónica, 2015).

Movistar Música es una plataforma digital de contenidos de música hecha en el Perú, creada el 2016 y perteneciente a la empresa Movistar (Telefónica de España), que ofrece videos y música de artistas peruanos a través de tres diferentes formatos: un canal de televisión por cable, una aplicación para teléfonos celulares y una página web (Bquate, 2016; Telefónica, 2016). Estos dos casos representan emprendimientos innovadores dentro de la industria musical nacional que buscan la convergencia de los medios de distribución convencionales con los digitales, ofreciendo nuevas oportunidades y espacios de difusión para los creadores de contenido.

En relación con los creadores de contenido nacionales y la adaptación de su rol de músicos a los cambios en la industria, podemos destacar los casos del grupo Corazón Serrano y de Lucho Quequezana. Corazón Serrano es un grupo musical de cumbia y ritmos tropicales fundado en 1995 y originario de la provincia de Ayabaca, en el departamento de Piura, que luego de seguir por muchos años el tradicional circuito artístico de shows en vivo como teloneros de grupos con mayor cartel, hacer grabaciones de covers (versiones propias de canciones de otros grupos) y, finalmente de temas propios, estableció una alianza estratégica el año 2011 con Radio Karibeña, radioemisora limeña con casi 100 filiales en todo el país perteneciente al grupo Corporación Universal. Esta alianza permitió que todas las nuevas canciones del grupo fueran emitidas en exclusividad por dicha radio, estrategia que ayudó al grupo a afianzarse en los gustos musicales del consumidor peruano 
de cumbia, llegando a ser en la actualidad su mayor exponente en el país (Bendezú, 2013; Corazón Serrano, s.f.).

Por otro lado, Lucho Quequezana, músico multinstrumentalista con una propuesta que fusiona la música tradicional andina instrumental con ritmos modernos, ha conseguido diferentes logros en su 15 años de carrera artística: su disco Kuntur fue el más vendido en el Perú en el año 2011, ha recibido diferentes reconocimientos y premios (la beca UNESCOAschberg el 2006, CONACINE en 2007, Ibermedia en 2009 y es Embajador Cultural del Perú), y Combi, su última producción musical, fue nominada a los premios Grammy Latino el año 2014, todo esto sin contar con una disquera y sin el apoyo de los medios tradicionales (radio, televisión, etcétera) locales. A pesar de ello, su música tiene una gran exposición en medios digitales, en donde ha focalizado su estrategia de promoción y difusión local y mundial, siendo capaz de tener un alcance de más de 1,5 millones de personas, realizar conciertos a través de medios digitales y conducir campañas promocionales de sus espectáculos dirigidas a 18 segmentos diferentes de su público objetivo (Eyzaguirre, 2016; Foppiano, 2016; Radio Antena Sur, 2016).

A diferencia de Corazón Serrano, enfocado principalmente en el mercado musical local — pequeño, pero con nichos altamente populares y competitivos—, Lucho Quequezana tuvo un acercamiento diferente a la industria musical, más acorde con una estrategia de difusión y promoción global digital, pero gestionada localmente, que es consistente con los cambios acaecidos en la industria musical mundial detallados anteriormente y que, para el caso de los músicos nacionales, abre oportunidades de expansión hacia nuevos mercados a costos asequibles y en menos tiempo que antes.

\section{Las sociedades de gestión colectiva}

En el proceso de cambio de paradigma de la industria, un actor muy importante se ha mantenido a la expectativa, teniendo que afrontar adaptaciones y sufriendo, al mismo tiempo, cuestionamientos: las sociedades de gestión colectiva (SGC), cuya principal e importante tarea en este mercado de USD 50000 millones es la de recaudar las regalías de los dueños del copyright generadas por las actividades de explotación de sus canciones. Los compositores, autores y ejecutantes de una obra musical tienen derechos patrimoniales sobre la misma, lo que significa que tienen potestad para decidir cómo va a ser utilizada por otros (traducción, explotación, adaptación); y, además, tienen derecho a recibir un ingreso por su reproducción y ejecución, el cual mantienen por un periodo de tiempo (usualmente 70 años luego de su fallecimiento). En la actualidad, tanto la legislación peruana como la internacional reconocen estos derechos; no obstante, no siempre fue así.

Inicialmente, los derechos relacionados a la propiedad intelectual se restringían a los libros y otras publicaciones (de acuerdo con el estatuto de la reina Ana para el Reino Unido, instaurado en 1709) por 14 años y eran renovables una sola vez. Ni la música ni sus autores estaban protegidos debido a que, tal como Kretschmer (2000) menciona en su investigación sobre la historia de la propiedad intelectual en la música, las editoriales de la época no estaban interesadas en dichos derechos dado que las canciones de moda no duraban lo suficiente como para invertir en lobbies y cambio de leyes. Durante el siglo XVIII los compositores musicales obtenían sus ingresos: a) ejecutando sus propias canciones u 
obras musicales en presentaciones en vivo; b) por medio de la venta de las partituras de sus temas, producidas por ellos mismos o mandadas a hacer; y c) a través de comisiones al realizar obras por encargo. Recién en el último cuarto del siglo XVIII las composiciones musicales se consideraron cubiertas dentro de la Ley de Anne, por lo que las editoriales comenzaron a inscribirlas para hacer negocio con la venta de las partituras; es decir, con su reproducción (Kretschmer, 2000).

Los derechos por ejecución surgieron como resultado de la aceptación de los derechos por reproducción de la obra musical. Así, a fines del siglo XVIII e inicios del siglo XIX, las leyes en Francia y en el Reino Unido ya reconocían el derecho del compositor sobre la ejecución pública de su obra por otro, y los tribunales comenzaron a fallar a favor de las demandas presentadas por compositores que exigían una indemnización a los locales donde su música era presentada (Kretschmer, 2000). Siguiendo esa línea, el autor Ernest Bourget, los compositores Paul Henrion y Victor Parizot, y el editorialista Jules Colombier fundan en 1851 la Sociedad de Autores, Compositores y Editoriales de la Música (SACEM) en Francia, el cual tenía la misión de brindar protección a sus miembros con respecto a los productores de entretenimiento y a los locales en donde se ejecutan obras musicales (SACEM, 2015). Esta institución es la primera sociedad de gestión colectiva y sigue funcionando hasta nuestros días.

\subsection{El sistema de gestión colectiva y el rol de las SGC}

Las sociedades de gestión colectiva (SGC) son asociaciones civiles sin fines de lucro creadas con el fin de defender los derechos patrimoniales de sus asociados y los derechos conexos relacionados, los mismos que deben ser reconocidos en las leyes sobre propiedad intelectual que rigen en cada país. En el caso del Perú, el D.L. 822 de 1996 reconoce estos derechos, además de normar la gestión colectiva de los mismos.

En el gráfico 3 se pueden apreciar los espacios de acción de las SGC y las relaciones existentes entre los distintos actores del sistema de gestión colectiva. La industria de la música se ve reflejada en este gráfico a través de la explotación de la obra musical, ya sea por su reproducción en productos musicales físicos o digitales (derechos mecánicos) e impresos (partituras), o por su interpretación en locales, estaciones de radio, shows en vivo, medios audiovisuales, etcétera (derechos por ejecución). Hay que tener en cuenta que los derechos mecánicos reconocen al autor de la obra musical, así como al productor de la misma, por lo que la compañía discográfica y la editorial también reciben ingresos por estos derechos recolectados por la SGC, mientras que los artistas vinculados con la ejecución de la música en el producto musical reciben los ingresos recolectados por la ejecución en dicho producto (Kretschmer et al., 1999). Por eso es posible que, por ejemplo, si una canción es reproducida en una película, tanto el compositor (de letra y música), el productor, los músicos que grabaron dicha pieza y la editorial con derechos contractuales negociados con el compositor, como la compañía disquera con derechos contractuales negociados con los músicos que la grabaron, reciban un ingreso, el cual es recolectado por la SGC. 


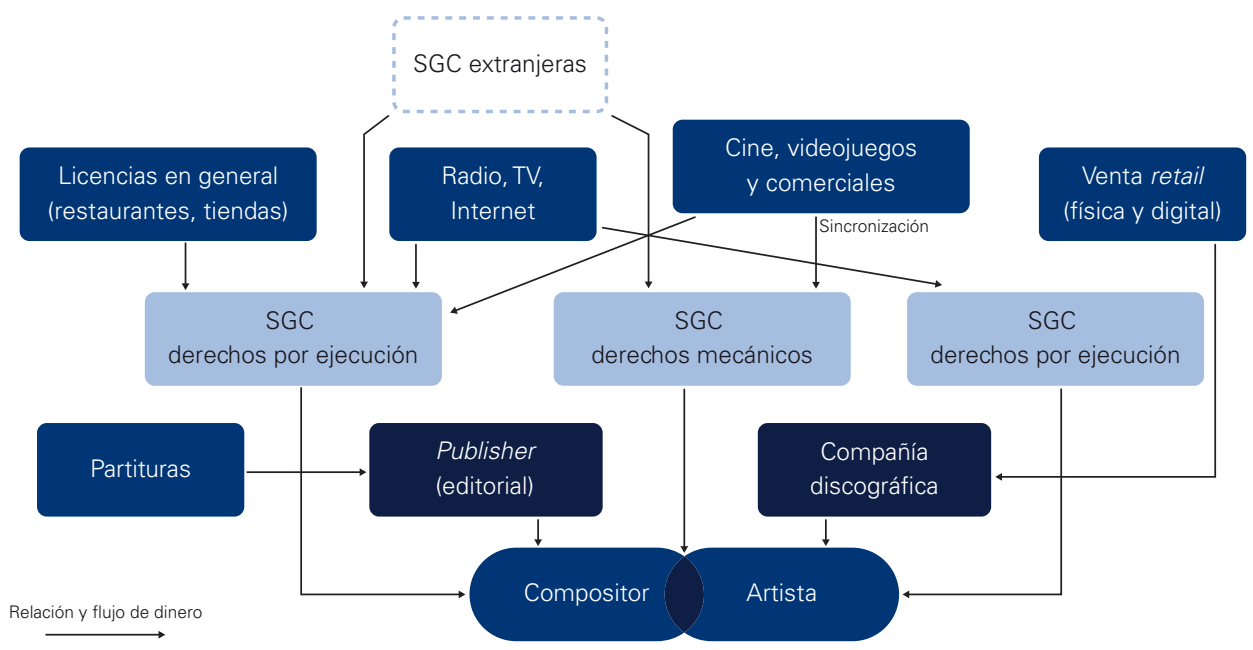

Fuente: adaptado de Kretschmer et al. (1999).

Las sociedades de gestión colectiva tienen en general cuatro funciones principales: a) licencian las obras cuyos derechos mantienen o por las que actúan como agentes, representando a sus miembros para usos específicos de estas; b) monitorean el uso de esas obras y recolectan los pagos por dichos usos; c) distribuyen los ingresos como regalías para sus miembros; y d) realizan acuerdos recíprocos con SGC del extranjero para velar por los derechos de sus miembros fuera del país y viceversa (Towse, 1999).

El hecho real es que un compositor/artista puede realizar contratos con una editorial o una compañía disquera y recibir las regalías por los usos «primarios» de su obra, ya sea por la venta de discos o como avances por su trabajo. En ese sentido, es en los usos "secundarios" en donde las SGC cumplen un rol fundamental, dado que los usos de una producción musical hechos por terceros, ya sea en otra grabación o una ejecución en vivo, no pueden ser controlados uno a uno por el compositor/artista. Es decir, los costos de transacción que se generan por esto son más altos $y$, al no haber incentivos para que dichos usuarios reconozcan los derechos del autor, este no recibe ingresos adicionales a los producidos por los usos primarios, sobre los cuales tiene derecho (Towse, 2006). Así, las SGC fueron principalmente creadas para poder gestionar los usos secundarios (este fue el motivo de la fundación de SACEM, por ejemplo), pero en la actualidad pueden agrupar la gestión de todos los ingresos generados por los derechos patrimoniales.

\subsection{Cuestionamientos a las SGC y los cambios en la industria}

Las SGC han sido objeto de críticas y cuestionamientos en los últimos años, no solo por los usuarios de las obras musicales (establecimientos, medios de comunicaciones, etcétera), sino también por sus propios miembros, debido esto último al problema de agencia que se presenta en estas organizaciones. La teoría de agencia trata sobre la relación contractual entre un principal (en este caso, los miembros de la SGC) que se relaciona con un agente (en este caso, las personas que asumen el rol de directivos de la SGC) para que ejecute 
actividades y servicios a su nombre, lo que implica delegar niveles de autoridad en la toma de decisiones (Jensen \& Meckling, 1976).

En esta relación el principal debe desarrollar incentivos adecuados y asumir costos de supervisión para evitar que el agente incurra en actividades que vayan en contra de sus intereses; sin embargo, el principal no puede supervisar completamente al agente en ambientes con mucha incertidumbre, lo cual genera un problema de agencia pues el agente oculta información y hechos al principal, que no tiene acceso a información sobre este (Pavlou, Liang \& Xue, 2007). Sobre el problema de agencia en las SGC, Besen, Kirby y Salop (1992) desarrollan un análisis de su impacto, el cual ha sido revisado y agrupado para este documento en los siguientes puntos: a) la distribución de los ingresos entre sus miembros, b) las tarifas y la forma en que cobran por las licencias, y c) la relación con sus miembros.

\subsubsection{Distribución de los ingresos}

Un aspecto del problema de agencia se manifiesta en la manera en que las SGC administran usualmente los contratos de explotación de las obras musicales: a través de licencias generales (blanket licences). Este tipo de licencias permite al usuario de la misma aprovechar todas las obras musicales del catálogo que representa la SGC por un pago fijo, el cual no varía sin importar cuántas obras utilice quien adquiere la licencia; al mismo tiempo, el usuario debe mantener un esquema de seguimiento y reporte de las canciones utilizadas, o reproducir una lista de canciones aprobadas por la propia SGC, inclusive en el extranjero a través de contratos recíprocos entre sociedades (McDonald, 2016; Towse, 1999). En este caso, y para minimizar los costos de transacción, las SGC pueden terminar desconociendo las contribuciones de autores individuales, ya sea por una identificación incompleta de la música y las composiciones consumidas o porque se dirige la oferta de canciones sin una supervisión previa de los principales. Ello beneficiaría a un grupo específico de artistas o aquellos con mayor demanda; y, por consiguiente, al grupo de editoriales que centralizan la mayoría de las obras musicales (Kretschmer, 2002; Towse, 2006).

Con respecto a la distribución de las regalías entre sus miembros, Towse (1999) y Kretschmer (2005) hicieron un análisis en el mercado inglés, alemán y danés sobre la distribución de regalías efectuada por las SGC de dichos países entre sus miembros a fines del siglo XX. Comparando diferentes periodos, llegaron a conclusiones parecidas: el promedio anual de regalías por miembro es muy bajo ( $€ 75$ ), existiendo un pequeño grupo de miembros que tienen ingresos superiores a las $f 10000$ al año (entre $1 \%$ y 6\%). Esta distribución de ingresos de tipo long tail refleja un mercado que, aunque prefiere y consume en gran cantidad un grupo pequeño de productos musicales, no deja de consumir, aunque en mucha menor cantidad, otros productos musicales (Pitt, 2010). No obstante, es importante acotar que el uso de contratos de licencias generales por parte de las SGC y los problemas de identificación de la obra musical consumida reforzarían una distribución

2. El concepto de long tail fue utilizado por Chris Anderson en su libro The Long Tail: Why the Future of Business is Selling Less of More, en donde muestra que las ventas en los negocios modernos presentan un comportamiento con una distribución de tipo Pareto, con pocos productos que se venden mucho (la cabeza de la curva) y muchos productos que se venden poco (la cola de la curva). 
de ingresos de este tipo, por lo que se estarían movilizando ingresos de los que reciben menos a los que reciben más.

\subsubsection{Tarifas y cobro}

En relación con las tarifas y su cobranza, esta última siempre ha generado quejas y pedidos de cambio en la regulación tanto de parte de los usuarios que explotan los productos musicales como del público en general que consume música. De acuerdo con la página web de la American Society of Composers, Authors and Publishers (ASCAP), SGC norteamericana y una de las más grandes del mundo, las tarifas varían de acuerdo a la manera en que se utiliza la música (shows en vivo, grabación, uso audiovisual, etcétera) y al tamaño del local o de la potencial audiencia (ASCAP, 2015), por lo que se tiene toda una parrilla de tarifas ajustables, dependiendo de la necesidad del cliente.

La estructura monopólica natural que el sistema legal le otorga a las SGC hace que sea muy difícil la negociación de parte de los usuarios al buscar un precio de equilibrio (Tavera \& Ore, 2006), por lo que los reclamos de estos tienden a exigir cambios legislativos que regulen y hagan más competitiva la legislación sobre la propiedad intelectual (Goss, 2007). El actuar de las SGC respecto a la forma de cobro por el uso de las obras musicales les ha generado una mala imagen frente al público en general, lo cual también termina produciendo un mayor soporte para posibles cambios regulatorios. Uno de los casos que generó polémica en EE. UU. se dio cuando la ASCAP quiso cobrar regalías a la American Camping Association por el uso de canciones tradicionales de campamento que cantaban las niñas scout (Bumiller, 1996); o, a nivel nacional, cuando la APDAYC, SGC peruana, quiso cobrar por cantar el «Cumpleaños feliz» en las fiestas familiares (Álvarez \& Aquino, 2013).

\subsubsection{Relaciones con los miembros}

Sin embargo, el problema de agencia se da con mayor énfasis en la relación con sus miembros y asociados (los principales), dado que los directivos y ejecutivos de estas instituciones (los agentes), aunque representan a sus miembros y son elegidos por ellos, también son compositores de canciones, por lo que tienen intereses personales directos en la gestión de la institución. Esto se ve reflejado en distintas acciones que evidencian poca transparencia y un muy bajo nivel de gobierno corporativo de parte de los directivos de las SGC, potenciado además por la estructura monopólica natural mencionada anteriormente.

Un ejemplo internacional de esto son las acciones realizadas por ASCAP y reportadas por Mark Holden (2005) en su artículo "ASCAP Since AFJ2 - A Series of Unfortunate Events", publicado en la revista digital Film Music Magazine, donde esta SGC, luego de lograr unos cambios regulatorios por vía judicial, procedió a realizar cambios y acciones como, por ejemplo, aumentar los requisitos para que los miembros postulen al directorio de la institución, elegir a los directivos obviando los procesos formales de elección, recategorizar a sus miembros para favorecer a algunos y discriminar a otros, prohibir el libre acceso de sus miembros a las actas del directorio, promover formas de votación basadas en el rating de pago de la institución (lo que refuerza la formación de un grupo dirigente pequeño no representativo de la mayoría), usar la información de un medio (encuesta de emisiones de 
canciones en la radio) como fuente para pagar los ingresos de otro medio (uso de canciones en la televisión por cable), etcétera. A nivel nacional, la SGC APDAYC ha presentado un comportamiento similar, el cual será analizado más adelante en este documento.

En el presente, la tecnología y los cambios en la industria mencionados anteriormente están comenzando a crear una separación de intereses entre los "creadores de contenido" y las SGC. Un ejemplo de esto es el uso de identificadores para las grabaciones digitales de la obra musical, como son el International Standard Recording Code (ISRC) y el Global Release Identifier (GRid), que buscan brindar una identificación única a las grabaciones en redes digitales (IFPI, 2015). El uso de estos identificadores en la distribución digital de las canciones permitirá una identificación más específica e individual durante la explotación del producto musical, ya sea por la venta física del mismo o en la venta por descarga, en la transmisión por radio tradicional o Internet, en los servicios tipo streaming, a través de videos en Internet y en el uso para la televisión o las películas.

Aunque esto facilita la explotación y el monitoreo del uso de la obra musical al propio artista/compositor, y permite que las SGC dejen de usar las licencias generales (blanket licences) como modelo usual, en los usos secundarios todavía no hay una solución del mismo nivel. A la fecha, la posibilidad de crear una base de datos global sobre la propiedad de las canciones todavía está pendiente dado que la iniciativa del Global Repertoire Database (GRD), que agrupaba a grandes empresas de música online como Apple, Amazon y Google con varias SGC y apuntaba a materializar ese logro tan importante para los compositores, fue suspendida debido a la falta de financiamiento, las disputas entre sus miembros sobre el control de la base de datos global y el interés de las SGC por buscar un sistema más eficiente (Edwards, 2016; Milosic, 2016; Resnikoff, 2014). En la medida que el compositor tenga mayor acceso a la información sobre la explotación de su obra musical, tendrá también más elementos que le brinden una mejor posición negociadora con las SGC y podrá ejercer mayor control sobre estas.

\section{Las sociedades de gestión colectiva en el Perú: el caso APDAYC}

En el Perú, el Decreto Legislativo 822 de 1996 —la Ley sobre el Derecho de Autorreconoce y protege al autor de las obras artísticas, identificándolo como la persona natural que realiza la creación intelectual u obra del ingenio. Reconoce asimismo la existencia de distintos derechos sobre las composiciones musicales, como los de los arreglistas musicales, los intérpretes o ejecutantes, y los productores de los fonogramas, además de normar el funcionamiento de las SGC, que tienen como fin defender los derechos patrimoniales reconocidos en la ley y son autorizadas y supervisadas por la Dirección de Derechos de Autor del Instituto Nacional de Defensa de la Competencia y de la Protección de la Propiedad Intelectual (INDECOPI).

En el país existen actualmente tres sociedades de gestión colectiva relacionadas con la industria musical y están directamente vinculadas con los derechos de los autores, productores y ejecutantes: la Asociación Peruana de Autores y Compositores (APDAYC), autorizada el año 1996; la Unión Peruana de Productores Fonográficos (UNIMPRO), autorizada el año 2001; y la Sociedad Nacional de Intérpretes y Ejecutantes de la Música (SONIEM), autorizada el año 2011. 
La gestión de la SGC APDAYC, la más antigua de todas (fundada en 1952), en cuanto a la recaudación de derechos de autor sigue el comportamiento del promedio de la industria a nivel mundial. Al revisar la memoria del año 2014 en su página web institucional (la última que figuraba en ella de manera pública a la fecha de presentación del presente artículo) se puede apreciar que el $60 \%$ de sus ingresos se encuentran en los rubros de locales permanentes, cadenas, televisión y cable, y radioemisoras, donde usualmente se trabajan con licencias generales. Asimismo, el 34\% lo recauda en bailes, espectáculos y megaconciertos, en donde las obras musicales a ser ejecutadas son responsabilidad de cada evento e informadas por ellos; y el 6\% restante se recauda de las SGC del extranjero y de otras fuentes (APDAYC, 2016). Estos números se pueden apreciar con mayor detalle en la tabla 1 y reflejan el comportamiento expresado en el cuestionamiento que se hace a la manera como las SGC gestionan el cobro de los derechos, pues al buscar la eficiencia en los costos de recaudación benefician a un grupo pequeño de miembros en desmedro de un grupo mayor.

Tabla 1. APDAYC: recaudación de derechos de autor por rubros

\begin{tabular}{l|c|c} 
rubro & $\mathbf{2 0 1 4}$ (soles) & \% \\
\hline Locales permanentes & 15453600 & $17 \%$ \\
\hline Bailes & 9938800 & $10 \%$ \\
\hline Espectáculos & 5715731 & $10 \%$ \\
\hline Cadenas & 5915723 & $7 \%$ \\
\hline Megaconciertos & 3840057 & $10 \%$ \\
\hline Televisión & 5523850 & $8 \%$ \\
\hline Cable & 4736298 & $5 \%$ \\
\hline Radioemisoras & 3024433 & $1 \%$ \\
\hline Derechos del extranjero & 761507 & $\mathbf{7 0 0 \%}$ \\
\hline Otros & 1620500 & $\mathbf{3 7 0 6 7 8 3 5}$ \\
\hline
\end{tabular}

Fuente: APDAYC (2014).

Por otro lado, la APDAYC definió como parte de su estrategia institucional que asumiría un mayor rol en el desarrollo de la industria musical peruana, de manera que además de dedicarse a la gestión de los derechos patrimoniales de sus asociados, que es aquello para lo que la Ley sobre el Derecho de Autor le faculta, buscó promover y gestionar la difusión de la música nacional. Para tal fin adquirió el 90\% del catálogo musical de las disqueras IEMPSA, EI Virrey, DIN, Disvensa y Sonoradio, que agrupa canciones de distintos artistas y géneros de música peruana de los últimos 70 años; compró y mejoró el estudio de grabación de IEMPSA; e invirtió en la adquisición de la cadena radial Inspiración FM, que cuenta con 12 filiales en el país, cuya gestión fue cedida el año 2013 a la Fundación Autor (APDAYC, 2013a, 2013b). 
Es así como, tomando en cuenta los roles dentro de la industria musical explicados anteriormente, la APDAYC, además de ser una SGC, se convirtió en una editorial que gestionaba la explotación de obras musicales, en una radioemisora que gestionaba la transmisión y difusión radial de canciones, y en una disquera al ofrecer servicios de grabación a los artistas que los necesiten, todo lo cual, en un mercado musical muy pequeño, le otorga una posición de dominio que requiere necesariamente de una gestión transparente en relación con sus asociados, que son la razón de ser de la institución. Esta posición de dominio se aprecia en los espacios sombreados del siguiente gráfico, que muestra la influencia de los roles que la APDAYC buscó asumir dentro del sistema de gestión colectiva nacional.

\section{Gráfico 4. APDAYC y el sistema de gestión colectiva}

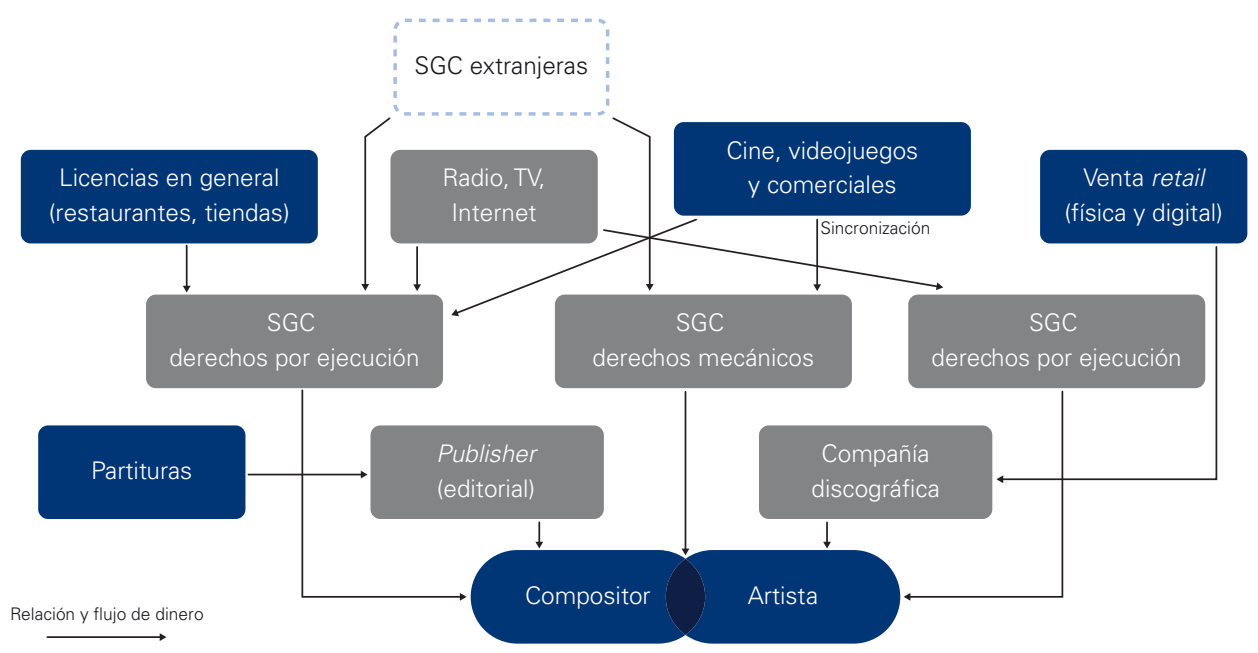

Fuente: adaptado de Kretschmer et al. (1999).

Por otro lado, a la luz de los cambios operados en la industria musical global, dicha estrategia sería consistente con una visión tradicional de la misma, en donde el artista (creador de contenido) necesita de un promotor (distribuidor de contenido) que lo ayude e impulse dentro de la industria, como fue en el caso del grupo Corazón Serrano. Sin embargo, esta no es la visión ni son los espacios de desarrollo adecuados para la industria actual de la música, donde incluso los medios tradicionales de comunicación (radio, televisión, cable) están en un proceso de transformación de sus modelos de negocio, cada vez más dirigidos hacia un mercado digital, y donde el caso de Lucho Quequezana es un ejemplo de la nueva forma que los creadores de contenido pueden emplear para gestionar su propio camino dentro de la industria y además ser agentes de cambio en ella.

Aunque la APDAYC puso el desarrollo de la industria musical peruana como el foco de su estrategia, su gestión en los últimos años ha tenido una serie de cuestionamientos en relación a la transparencia y al gobierno corporativo, los mismos que se han hecho públicos y han terminado generando varias multas y suspensiones de parte del INDECOPI (El Comercio, 2016; Gestión, 2015a, 2016; INDECOPI, 2013, 2014; La República, 2015a; Murillo Chávez, 2016; Peru21, 2013). Cabe señalar que la situación legal de la APDAYC, 
como del sistema de las SGC peruano, está siendo revisada en el Congreso de la República, habiéndose presentado 12 proyectos de ley hasta marzo del 2015 (Collao Vera, 2015). Asimismo, actualmente existe un proyecto de ley de modificación de diversos artículos del D.L. 822 en la Comisión de Defensa del Consumidor y Organismos Públicos Reguladores de los Servicios Públicos del Congreso (Proyectosdeley, 2018), lo que, de producirse, cambiaría la cobertura y alcance de las SGC, así como su relación con la gestión de los derechos de autor musicales.

Con respecto a estos cuestionamientos, los periodistas Marco Sifuentes y Jonathan Castro (2014) investigaron la gestión de la APDAYC en los últimos años y encontraron acciones que están vinculadas con el problema de agencia y la estructura monopólica —al igual que en el caso ASCAP mencionado anteriormente - como, por ejemplo, las restricciones a sus miembros en las elecciones del consejo directivo, la presencia de personas que ostentan el cargo de directores tanto en empresas editoriales como en el consejo directivo de la APDAYC y el cobro por obras musicales que no están dentro del catálogo gestionado por la APDAYC, entre otras.

Estas denuncias periodísticas y las investigaciones subsiguientes llevaron en marzo del año 2014 al INDECOPI a suspender al consejo directivo de la APDAYC por infracciones a la Ley de Derecho de Autor, designando una junta administradora que ejercería las labores del consejo directivo suspendido (Gestión, 2014), lo cual fue apelado por la APDAYC, pero confirmado por la sala especializada en propiedad intelectual del INDECOPI en junio del 2016 (El Comercio, 2016; INDECOPI, 2016). A la fecha de la presentación del presente artículo, este proceso todavía seguía su proceso en la vía administrativa y judicial.

\section{Respuestas y alternativas al sistema de gestión colectiva}

Tal como se ha visto en la presentación y la crítica al sistema de la gestión colectiva, los miembros de la SGC no tienen los medios para supervisar el accionar de los directores de la SGC y negociar el acceso a la información relevante; por ende, no pueden conocer con certeza si estos actúan en función del beneficio colectivo o si lo hacen en función de un grupo pequeño y seleccionado por ellos mismos, situación que también afecta a las editoriales, que pueden tener derechos patrimoniales sobre las canciones.

Estas editoriales han comenzado a explorar un nuevo camino en su relación con las SGC, el cual ha generado muchas expectativas para todos los creadores de contenido: el licenciamiento directo o direct licensing. En esta situación, el interesado en explotar el producto musical puede ir directamente a la fuente —en este caso la editorial con derechos sobre el producto- y negociar por el uso de dicho producto o de un catálogo musical, saltándose al intermediario: la SGC. La intención final es ahorrar los costos que genera la gestión de las SGC en el proceso, además de eliminar a un actor dentro de la negociación (Pitt, 2010).

Esto ha generado que los propios artistas y compositores comiencen a trabajar con la negociación directa de sus productos musicales, mejorando su posición negociadora con respecto a las SGC o incluso desafiliándose de las mismas y trabajando por su cuenta a través de nuevos modelos de negocio. Buenos ejemplos de esto son la relación contractual entre Madonna y Live Nation, que ha priorizado los shows en vivo y el merchandising 
antes que las grabaciones; grupos como Artic Monkeys y Radiohead, que colocan gratis su música en Internet para sus seguidores, pero negocian con empresas de software para que sus canciones vengan cargadas en los sistemas operativos; o grupos como Journey, que negocian directamente la venta de sus productos con Walmart (David, 2010; Pitt, 2010).

Estos ejemplos están mostrando nuevos caminos a los creadores de contenido que les permitan vivir de su arte musical, minimizando la importancia de los intermediarios, pero implicando también una cierta pérdida de control sobre el uso de sus obras; mientras que en el modelo tradicional de gestión colectiva siguen dándose quejas y controversias en torno a las SGC en países como Alemania, Australia, EE. UU., Francia y España, por nombrar alguno casos (Berretta, 2010; Deutscher Bundestag, 2009; Ferreiro, 2010; Pilcher, 2009; Prieto, 2017), lo que indica la existencia de un problema complejo que no está localizado en una organización en particular.

Pero, ¿este problema es resultado de la estructura del sistema o de las personas que gestionan dicha estructura? La respuesta es: de ambas. El sistema de gestión colectiva responde a una estructura de relaciones resultado de la interacción de distintos actores vinculados con la industria musical. La normativa resultante, que da forma a las SGC, busca empoderarlas dentro de dicho sistema con la finalidad de defender los derechos de autor y que las SGC los administren y exploten adecuadamente. Si este rol no existiera dentro del sistema, se limitaría la generación de ingresos para los creadores de contenido por sus obras dado el alto costo que supondría controlar y supervisar su explotación.

Es por eso que afirmamos que el principal valor de las SGC es el efectivo uso de sus recursos en las actividades de seguimiento —es decir, su eficacia en la identificación de la explotación de las obras musicales, distribuyendo lo recaudado según lo consumidoy la eficiencia de su gestión (según la ley peruana, las SGC pueden destinar hasta el 30\% de los ingresos a gastos administrativos). En mercados musicales de mayor tamaño como el norteamericano, la existencia de varias SGC que compiten por ofrecer mejores servicios a sus asociados, además de brindar distintas opciones de explotación a los consumidores de música, debería ayudar a regular el comportamiento de dichas organizaciones y asegurar el beneficio de sus asociados; sin embargo, Besen, Kirby y Salop (1992) hicieron un análisis económico del uso de las licencias generales (blanket licences) en un entorno con varias SGC en competencia, encontrando que esta forma de recaudación: a) otorga a los usuarios de las licencias un gran porcentaje del excedente, dado que el costo de las licencias disminuye; b) debido a dicha disminución, es posible que no se lleguen a cubrir los costos administrativos; y c) los ingresos de los asociados disminuyen, lo que se traduce en una pérdida de membresía para las SGC.

Esto nos muestra que la estructura sobre la que funcionan las SGC tiene que cambiar, buscando mejorar el proceso de identificación del uso de las canciones y la distribución de las ganancias a los respectivos autores según dicho uso, siempre cuidándose de ser eficientes con el gasto, lo cual es perfectamente factible si se aprovecha la transformación de la industria musical hacia un entorno digital. El caso de SACEM (2017), la SGC francesa, es una muestra de estos avances: en su reporte anual del año 2016 indican que han repartido $€ 884,3$ millones en derechos de autor a más de 298000 compositores y editoriales alrededor del mundo, logrando un $80 \%$ de identificación individual (work-by-work) y definiendo el restante a través de reportes y encuestas (11\%), y de hábitos de consumo (9\%). 
En relación con las personas que gestionan la estructura, una alternativa podría ser la minimización del problema de agencia a través de la mirada de la teoría del stewardship o la administración responsable. Este marco teórico fue desarrollado por Donaldson y Davis (1991) como contrapartida a la teoría de agencia y tiene la finalidad de trabajar con elementos no necesariamente económicos que alineen los intereses del principal y del agente, buscando mostrar los beneficios que existen para la organización cuando el principal y el agente comparten los mismos intereses y roles, en lugar de poner énfasis en el control y los incentivos necesarios para evitar conductas oportunistas de parte de los segundos.

El rol del steward (guardián o cuidador) en la organización, además de tener que presentar una alta motivación intrínseca y de autorrealización, estaría enfocado en el cumplimiento de objetivos colectivos a través de un comportamiento cooperativo, buscando alinear los objetivos del principal con sus objetivos personales, valorando el compromiso y la confianza como un medio para lograr la identificación con la organización (Davis, Schoorman \& Donaldson, 1997).

En esa lógica, se puede desarrollar una organización con comportamientos de tipo stewardship luego de institucionalizar: a) mecanismos que permitan gestionar y mantener la confianza interorganizacional en un nivel alto a través de la responsabilidad personal y el desarrollo de competencias, como el pensamiento crítico y reflexivo; y b) mecanismos que permitan minimizar las tentaciones oportunistas a través de la autorregulación (transparencia y cooperación), la regulación de pares y los controles externos (Segal \& Lehrer, 2012), pero teniendo en cuenta que las personas que asuman los cargos directivos en la institución deben reunir el perfil de steward necesario, y que los miembros de la misma deben reconocerlos como tales y trabajar con ellos para el logro de los objetivos de los principales y de la institución. Sobre este tema, y tomando nuevamente el caso de SACEM, la SGC francesa fue duramente criticada el año 2010 cuando se conoció sus dirigentes evadían el rol de steward al remunerarse con sueldos que oscilaban entre $€ 250000$ y $€ 300000$, que la organización presentaba una gran disparidad entre los salarios de los funcionarios y los demás empleados de la misma, y que los gastos en viáticos no correspondían a las políticas de austeridad debidas (Berretta, 2010).

El caso de la APDAYC presenta los mismos retos que impone este complejo problema, al que hay que añadir el tamaño del mercado de la industria musical peruana y los problemas relacionados con la piratería, los consumos ilegales y la baja penetración del consumo digital mencionados anteriormente. Sin embargo, el rol de una SGC en el desarrollo de la industria musical nacional no consiste en repetir o focalizarse en estrategias de entornos del siglo pasado que, además, dan espacio a conductas alejadas del objetivo social de la institución (Sifuentes \& Castro, 2014), sino en invertir para mejorar la identificación de la explotación de las obras musicales, desarrollar convenios con los grandes consumidores de música locales que permitan el uso de plataformas digitales de control, promover el consumo de composiciones y la música de autores y artistas nacionales a nivel internacional, mejorar los sistemas de información y reporte para los asociados de las SGC, y apoyar a los creadores de contenido (artistas y compositores) en el desarrollo de las habilidades necesarias para la promoción y difusión de su obra en un entorno digital de alcance global. Esto último es especialmente importante dado que el desarrollo de la industria musical nacional no se reduce solamente a incrementar su consumo localmente, 
sino que también requiere incrementar el consumo global de la misma, tal como sucedió con la industria musical coreana (Shim, 2006; The Economist, 2010) o, para mencionar un ejemplo más cercano, con la industria musical colombiana (Bernstein, Sekine \&Weissman, 2007; BOmm, 2017; Cepeda, 2010; Padilla, 2017).

\section{Reflexiones finales}

El presente artículo analizó los nuevos roles que asumen y los retos a los que se enfrentan tanto los creadores como los distribuidores de contenido en el contexto de cambio de paradigma que se viene dando en la industria musical; y cómo las sociedades de gestión colectiva, instituciones creadas para administrar los derechos propietarios y la explotación de la obra de dichos creadores, se han enfrentado a dichos cambios, generando avances importantes y recibiendo a la vez muchas críticas y cuestionamientos en el proceso, no solo de parte de los consumidores de música, sino también de sus propios asociados, a los cuales la sociedad de gestión colectiva debe representar.

Los cambios en la industria musical han dirigido las estrategias de desarrollo hacia un mercado digital tanto en la producción y grabación de las obras musicales como en su promoción, distribución y comercialización, afianzando por un lado el rol del artista como ejecutante de obras musicales y productor de las mismas, y por el otro la concentración del negocio editorial musical, consolidando el rol del compositor y de los derechos patrimoniales explotables de su obra musical. En relación a dicha explotación, las SGC son un actor principal que representa a los creadores de contenido en la gestión del cobro producto de la misma, pero la estructura del sistema y la falta de incentivos adecuados genera entre estos y los gestores de la SGC problemas de agencia que no se han resuelto todavía, situación que se ha repetido en varios países y que, a nivel local, se refleja en el caso de la APDAYC, SGC con serios problemas de agencia que a la fecha siguen sin solución.

Finalmente, se analizó cómo los cambios tecnológicos y los nuevos modelos de negocio en la industria de la música permiten vislumbrar una oportunidad para generar mayor transparencia en el accionar de las SGC, además de una mejor supervisión por parte de los compositores asociados a estas. No obstante, a nivel local es necesaria una acción fundamental para consolidar ese logro: la revisión de las normas vinculadas a la gestión de las SGC nacionales y su relación con las SGC del extranjero. Así, las normas deben apoyar la generación de incentivos para promover conductas del tipo stewardship y la colocación de controles adecuados que permitan minimizar un accionar en contra de los intereses de los miembros de las SGC, además de actualizarse ante las nuevas demandas de la industria musical global.

En el Perú se está ante la inmejorable oportunidad de modernizar la legislación sobre derechos de autor a la luz de los recientes acontecimientos, los cambios de la industria mencionados y los avances tecnológicos globales, oportunidad que esperamos no sea desaprovechada. Nietzsche decía "sin música la vida sería un error», y aunque los problemas relacionados con los derechos de autor no disminuyen la creatividad de los compositores y artistas musicales nacionales, es necesario facilitarles la vida por lo que la música significa para todos nosotros. 


\section{bibliografía}

\author{
Álvarez, I. \& R. Aquino \\ 2013 \\ Indecopi plantea acabar con cobros de \\ APDAYC a eventos privados. Recuperado \\ de: <http://elcomercio.pe/lima/sucesos/ \\ indecopi-plantea-acabar-cobros-apdayc- \\ privados 1-noticia-1646513> (consultado el \\ 8 de diciembre del 2015)

\section{Amorós, 0.} \\ 2014 \\ Muevan la industria... musical. Recuperado \\ de: <http://www.revistavelaverde.pe/ \\ muevan-la-industria-musical/> (consultado \\ el 10 de enero del 2017).
}

\section{Asociación Peruana de Autores y Compositores (APDAYC)}

APDAYC y su apuesta por el desarrollo de la industria musical en el Perú. Recuperado de: <http://apdaycperu.blogspot. pe/2013/05/apdayc-y-su-apuesta-por-eldesarrollo.html>

Cadena Inspiración FM apoya a artistas peruanos. Recuperado de: <http:// apdaycperu.blogspot.pe/2013/03/la-radiode-los-autores-inspiracion-fm.html> (consultado el 10 de enero del 2017).

Memoria 2014. Recuperado de: <http://www.apdayc.org.pe/images/ rocketlauncher/pages/memorias/ MEMORIA_2014.pdf>.

Pagina web institucional. Recuperado de: <http://www.apdayc.org.pe/> (consultado el 21 de agosto del 2016).

\section{American Society of Composers, Authors and Publishers (ASCAP)}

www.ascap.com/licensing/licensingfaq.

aspx\#general> (consultado el 8 de diciembre del 2015).

\section{Bendezú, R.}

2013

Corazón Serrano, el inexplicable fenómeno musical. La República, 31 de diciembre. Recuperado de: <http://larepublica.pe/3012-2013/corazon-serrano-el-inexplicable-

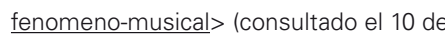
enero del 2017).

\section{Bernstein, A.; N. Sekine \& \\ D. Weissman}

The Global Music Industry: Three Perspectives. Nueva York: Routledge. Bernui, C. (2016). Bquate: el puente entre los músicos y el mundo. Recuperado de: $<$ http://www.timov.la/article/bquate-elpuente-entre-los-musicos-y-el-mundo-1> (consultado el 10 de enero del 2017).

\section{Berretta, E.}

2010

Comment la SACEM se goinfre... Recuperado de: <http://www.lepoint.fr/ actualites-medias/2010-04-10/commentla-sacem-se-goinfre/1253/0/442942> (consultado el 10 de enero del 2017).

\section{Besen, S. M.; S. N. Kirby \& S. C. Salop}

An economic analysis of copyright collectives. Virginia Law Review, 78(1), 383-411.

\section{BOmm.}

Bogotá, epicentro de negocios de la industria musical. Recuperado de: $<$ https://www.bogotamusicmarket.com/ Actualidad/2017/Septiembre/Bogotaepicentro-de-negocios-de-la-industria-

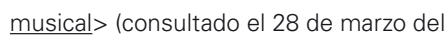
2018). 


\section{Bquate}

2016

Movistar Música llega a Perú.

Recuperado de: <https://medium.com/@

bquate/movistar-música-llega-a-perú-

25d84818d716\#.vngn5ftpj) (consultado el

10 de enero del 2017).

\section{Britten, A.}

2009

Working in the Music Industry. Oxford:

How To Content.

\section{Bumiller, $\mathrm{E}$.}

1996 ASCAP asks royalties from girl scouts, and regrets it. New York Times. Recuperado

de: <http://www.nytimes.com/1996/12/17/

nyregion/ascap-asks-royalties-from-girl-

scouts-and-regrets-it.html?pagewanted=1>

(consultado el 8 de diciembre del 2015).

Cepeda, M. E.

2010 Musical ImagiNation: U.S.-Colombian Identity and the Latin Music Boom. Nueva York: New York University Press.

\section{Collao Vera, M. B.}

2015

¿Cómo va la reforma de la Ley sobre

Derechos de Autor? Hiperderecho.

Recuperado de: <http://www.hiperderecho.

org/2015/03/reforma-derechos-autor/>

(consultado el 1 de enero del 2015).

\section{Corazón Serrano}

n.d. Corazón Serrano - Historia. Recuperado de: $<$ http://corazonserrano.net/> (consultado el 10 de enero del 2017).

\section{David, $\mathbf{M}$.}

2010 Peer to Peer and the Music Industry. The Criminalization of Sharing. Londres: Sage Publications.
Davis, J.; F. Schoorman

\& L. Donaldson

1997

Toward a stewardship theory of management. The Academy of

Management Review, 22(1), 20-47.

\section{Donaldson, L. \& J. H. Davis}

1991 Stewardship theory or agency theory:

CEO governance and shareholder returns. Australian Journal of Management, 16(1), 49-64.

\section{Edwards, A.}

2016 Who will build the music industry's global rights database? Music Bussines Worldwide, 15 de febrero. Recuperado de: $<$ http://www.musicbusinessworldwide. com/who-will-build-the-music-industrysglobal-rights-database/> (consultado el 10 de enero del 2017).

\section{El Comercio}

2014 La época de oro de los discos de vinilo fabricados en Perú. 23 de diciembre. Recuperado de: <http://elcomercio. pe/economia/peru/epoca-oro-discosvinilo-fabricados-peru-noticia-1780303> (consultado el 10 de enero del 2017).

Multan a APDAYC con S/ $118 \mathrm{mil}$

por irregularidades en regalías. 7 de junio. Recuperado de: <http:// elcomercio.pe/sociedad/lima/multanapdayc-s118-mil-irregularidadesregalias-noticia-1907543?ref=flujo_ tags $21305 \& \mathrm{ft}=$ nota $2 \& \mathrm{e}=$ titulo $>$ (consultado el 21 de agosto del 2016). 


\section{bibliografía}

\section{Eyzaguirre, M.}

2016

El curioso caso de Lucho Quequezana.

Semana Económica, 9 de marzo.

Recuperado de: <http://semanaeconomica.

com/hagamosclic/2016/03/09/el-curioso-

caso-de-lucho-quequezana/> (consultado el

10 de enero del 2017).

\section{Foppiano, G.}

2016

Negocios musicales: ¿se puede vivir del

arte en el Perú? Lima: UPC.

\section{Gestión}

2014

Indecopi suspende por un año al

consejo directivo de APDAYC y ordena

instalar junta administradora. 3 de

marzo. Recuperado de: <http://gestion.

pe/economia/indecopi-suspende-ano-

al-consejo-directivo-apdayc-y-ordena-

instalar-junta-administradora-2090624>

(consultado el 8 de diciembre del 2015).

$2015 a$

Indecopi declaró nulidad de los registros

de tres instancias del APDAYC. 7 de

enero. Recuperado de: <http://gestion.

pe/economia/indecopi-declaro-nulidad-

registros-tres-instancias-apdayc-2119648>

(consultado el 1 de enero del 2015).

Los videojuegos ya aportan el $62 \%$ de ventas de Phantom. 11 de diciembre.

Recuperado de: <http://gestion.pe/

empresas/videojuegos-ya-aportan-62-

ventas-phantom-2150831> (consultado el

10 de enero del 2017).

$2015 c$

PwC: industria cinematográfica peruana

crecerá $11.3 \%$ al año pero la musical

caerá 5.3\%. 14 de setiembre. Recuperado

de: <http://gestion.pe/mercados/pwc-

industria-cinematografica-peruana-crecera- 113-al-ano-musical-caera-53-2142741>

(consultado el 10 de enero del 2017).

2016

Indecopi confirma suspensión temporal

del consejo directivo de APDAYC.

3 de junio. Recuperado de: <http:/l

gestion.pe/economia/indecopi-confirma-

suspension-temporal-consejo-directivo-

apdayc-2162445 > (consultado el 21 de

agosto del 2016).

\section{Goss, A.}

2007

Codifying a commons: Copyright, copyleft, and the creative commons project.

Chicago-Kent Law Review, 1106(2005), 963-996.

\section{Handke, C.}

Plain destruction or creative destruction?

Copyright erosion and the evolution of the record industry. Review of Economic Research on Copyright Issues, 3(2), 29-51.

\section{Holden, M.}

2005

ASCAP Since AFJ2 - A Series of Unfortunate Events. Film Music Magazine, 22 de mayo. Recuperado de: <http://www. filmmusicmag.com/?p=529 $>$ (consultado el 8 de diciembre del 2015).

\section{Hull, G. P.; T. Hutchison \&}

\section{R. Strasser}

2010

The Music Business and Recording Industry. Nueva York: Routledge.

\section{IEMPSA}

Página web. Recuperado de: < http://www. iempsa.pe/> (consultado el 10 de enero del 2017). 
International Federation of the Phonographic Industry (IFPI)

2006

Digital formats continue to drive the global music market - World sales 2005.

Comunicado de prensa, 31 de marzo.

2015

Looking for industry knowledge?

Recuperado de:<http://www.ifpi.org/GRid. php> (consultado el 8 de diciembre del 2015).

IFPI Global Music Report 2016. 12 de abril. Recuperado de:<http://www.ifpi.org/ news/IFPI-GLOBAL-MUSIC-REPORT-2016> (consultado el 21 de agosto del 2016).

2017 IFPI Global Music Report 2017.

Recuperado de:<http://www.ifpi.org/globalstatistics.php> (consultado el 28 de marzo del 2018).

\section{Instituto Nacional de Defensa de la Competencia y de la} Protección de la Propiedad Intelectual (INDECOPI)

INDECOPI dicta medida cautelar suspendiendo regalías a los miembros del consejo directivo de APDAYC.

Recuperado de: <http://www.indecopi.gob pe/0/modulos/NOT/NOT_DetallarNoticia. aspx?PFL $=0 \& N O T=705>$ (consultado el 25 de setiembre del 2015).

INDECOPI suspende al consejo directivo de APDAYC y ordena instalación de una junta administradora. Recuperado de: <http://www.indecopi.gob.pe/0/ modulos/NOT/NOT_DetallarNoticia. aspx?PFL=0\&NOT $=781>$ (consultado el 25 de setiembre del 2015)
Jensen, M. C. \& W. H. Meckling

Theory of the firm: Managerial behavior, agency costs and ownership structure. Journal of Financial Economics, 3(4), 305360.

\section{Jones, A. C. \& R. J. Bennett}

2015

The Digital Evolution of Live Music.

Waltham, Massachusetts: Elsevier Ltd.

\section{Kretschmer, M.}

2000

Intellectual property in music: A

historical analysis of rethoric and institutional practices. Studies in Cultures, Organizations and Societies, 6(noviembre), 197-223.

Copyright societies do not administer individual property rights: The incoherence of institutional traditions in Germany and the UK. En R. Towse (ed.), Copyright in the Creative Industries (pp. 140-164). Cheltenham, Gloucestershire: Elgar.

Artists' earnings and copyright: A review of british and german music industry data in the context of digital technologies. First Monday, 10(1).

\section{Kretschmer, M.; G. M. Klimis}

\section{\& R. Wallis}

1999 The changing location of intellectual property rights in music: A study of music publishers, collecting societies and media conglomerates. Prometheus, 17(2), 163186. 


\section{bibliografía}

\section{La República}

2015a APDAYC es sancionada por infringir legislación de Derechos de Autor. 7 de enero. Recuperado de: <http://larepublica. pe/07-01-2015/apdayc-es-sancionada-porinfringir-legislacion-de-derechos-de-autor> (consultado el 25 de setiembre del 2015).

BQUATE ganó el concurso IBM

SmartCamp. 16 de setiembre. Recuperado de: <http://larepublica.pe/empresa/703941bquate-gano-el-concurso-ibm-smartcamp> (consultado el 10 de enero del 2017).

\section{McDonald, $\mathrm{H}$.}

What is a blanket license and how is it used in the music industry? The Balance Careers, 23 de julio. Recuperado de: $<$ https://www.thebalance.com/blanketlicense-in-the-music-industry-2460916> (consultado el 10 de enero del 2017).

\section{McKinney, K.}

No crowds, no tickets, no problem: What the concerts of the future might look like. Splinter, 19 de mayo. Recuperado de: $<$ http://fusion.net/story/302587/concertlive-streaming-music-future) (consultado el 10 de enero del 2017).

\section{Milosic, $\mathrm{K}$.}

2016 The failure of the global repertoire database. Hypebot.com. Recuperado de: <http://www.hypebot.com/ hypebot/2015/08/the-failure-of-the-globalrepertoire-database-effort-draft.html> (consultado el 10 de enero del 2016).

\section{Murillo Chávez, J. A.}

\section{Navas Rosal, Á.}

2015

Según PwC, así será la industria de la música en 2019. Industria Musical, 25 de junio. Recuperado de: <http:// industriamusical.es/segun-pwc-asisera-la-industria-de-la-musica-en-2019/> (consultado el 8 de diciembre del 2015).

\section{Nielsen Company}

The Nielsen Company \& Billboard's 2012 Music Industry Report. Business Wire, 4 de enero. Recuperado de: $<$ http://www.businesswire.com/news/ home/20130104005149/en/NielsenCompany-Billboard's-2012-Music-IndustryReport> (consultado el 8 de diciembre del 2015).

\section{Padilla, S.}

Estas son las razones del buen momento por el que pasa la industria musical. El Espectador, 16 de setiembre. Recuperado de: <https://www.elespectador.com/ economia/estas-son-las-razones-del-buenmomento-por-el-que-pasa-la-industriamusical-articulo-713477> (consultado el 28 de marzo del 2018).

\section{Pavlou, P. A.; H. Liang \& Y. Xue} relationships: A principal-agent perspective. MIS QUarterly, 31(1), 105-136.

\section{Peru21} Indecopi multa con S/. 81,400 a APDAYC por compra ilegal de radios. $11 \mathrm{de}$ setiembre. Recuperado de: <http://peru21. pe/actualidad/indecopi-multa-s81400apdayc-compra-ilegal-radios-2148754> (consultado el 25 de setiembre del 2015). 
Pitt, I. L.

2010 Economic Analysis of Music Copyright. Nueva York: Springer.

\section{Proyectosdeley}

2018 Proyecto de Ley 00622. 11 de noviembre.

Recuperado de: <http://proyectosdeley. pe/p/r8y5at/seguimiento/> (consultado el 28 de marzo del 2018)

\section{PuntoEdu}

2015

La escena musical peruana bajo la lupa. 9 de noviembre. Recuperado de: <http:// puntoedu.pucp.edu.pe/noticias/la-escenamusical-peruana-bajo-la-lupa/> (consultado el 10 de enero del 2017)

\section{PwC}

Global entertainment and media outlook 2016-2020. Recuperado de: <http://www. pwc.com/gx/en/industries/entertainment-

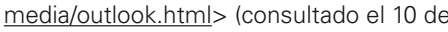
enero del 2017).

\section{Radio Antena Sur}

Lucho Quequezana: "Ahora se viene el boom de la música peruana». Recuperado de: $<$ http://www.radioantenasur. com/2016/12/19/lucho-quequezana-ahorase-viene-el-boom-de-la-musica-peruana/> (consultado el 10 de enero del 2017).

\section{Resnikoff, P.}

Global repertoire database declared a global failure... Digital Music News, 9 de julio. Recuperado de: <http://www. digitalmusicnews.com/2014/07/10/globalrepertoire-database-declared-global-failure/> (consultado el 8 de diciembre del 2015).
Société des Auteurs, Compositeurs et Éditeurs de Musique (SACEM)

Historical background. Recuperado de: $<$ https://societe.sacem.fr/en/history> (consultado el 7 de diciembre del 2015).

Annual Report and Accounts. 6 de junio. Recuperado de: <https://societe.sacem. fr/en/news/our-society/annual-report-andaccounts-2016> (consultado el 28 de marzo del 2018).

\section{Segal, L. \& M. Lehrer}

2012 The institutionalization of stewardship: Theory, oropositions, and insights from change in the Edmonton public schools. Organization Studies, 33(2), 169-201.

\section{Shim, D.}

2006 Hybridity and the rise of Korean popular culture in Asia. Media, Culture \& Society, 28(1), 25-44.

\section{Sifuentes, $M$.}

2013 APDAYC, el negocio familiar de Armando Massé. La República, 3 de octubre. Recuperado de: <http://larepublica. pe/30-10-2013/apdayc-el-negocio-familiar$\underline{\text { de-armando-masse }}>$ (consultado el $10 \mathrm{de}$ enero del 2017).

\section{Sifuentes, M. \& J. Castro}

\#intervenganAPDAYC. Recuperado de: <http://utero.pe/category/ intervenganapdayc) > (consultado el 9 de diciembre del 2015). 


\section{bibliografía}

Smirke, R.

2015 Global Record Business Dips Slightly,

U.S. Ticks Upwards In IFPI's 2015 Report.

Billboard, 4 de abril. Recuperado de:

$<$ http://www.billboard.com/articles/

business/6531734/ifpi-report-2015-us-

recording-industry-up-2-percent-global-

drop> (consultado el 8 de diciembre del

2015).

\section{Tavera, J. \& T. Ore}

2006

Gestión colectiva de derechos de autor: una mirada al caso peruano. Revista de la Competencia y la Propiedad Intelectual, (5).

\section{Telefónica}

Bquate distribuye los contenidos

musicales de más de 600 artistas latinoamericanos. Recuperado de: <http:// www.telefonica.com.pe/saladeprensa/ noticias/2015/24112015.shtml> (consultado el 10 de enero del 2017).

Multiplataforma digital para difundir la música hecha en el Perú. Recuperado de: <http://www.telefonica.com.pe/ saladeprensa/noticias/2016/09082016-full.

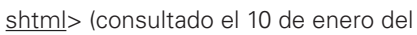
2017).

\section{The Economist}

2010

Hallyu, yeah! 25 de enero. Recuperado

de:<http://www.economist.com/

node/15385735> (consultado el 10 de enero del 2017).

\section{Towse, $\mathbf{R}$.}

1999

Copyright and economic incentives: An application to performers' rights in the music industry. Kyklos, 52(3), 369-390.

\section{Towse, $\mathbf{R}$.}

Copyright and artists: A view from cultural economics. Journal of Economic Surveys, 20(4), 567-585

\section{Weiser, B.}

Birthday song's copyright leads to a lawsuit for the ages. The New York Times, 13 de junio. Recuperado de: <http://www. nytimes.com/2013/06/14/nyregion/lawsuitaims-to-strip-happy-birthday-to-you-of-itscopyright.html? $r=0$ > (consultado el 4 de diciembre del 2015).

Fecha de recepción: 16/09/2016

Fecha de aceptación: 14/11/2016 